\title{
Importance of syngap1 syndrome diagnosis in autism spectrum disorder for dental treatment
}

\author{
Importância do diagnóstico de síndrome syngap1 no transtorno \\ do espectro autista para o tratamento odontológico
}

\author{
Adriana Gledys ZINK ${ }^{1}$ iD https://orcid.org/0000-0001-7005-5689 \\ Marcelo Diniz de PINHO² iD https://orcid.org/0000-0002-9726-9406 \\ Marcel Zink de PINHO² iD https://orcid.org/0000-0003-2274-0328 \\ Fernando Baeder de MARTINS² ID https://orcid.org/0000-0001-7101-5689
}

\section{ABSTRACT}

This paper reports on a patient with initial clinical diagnosis of Autism Spectrum Disorder level 3 and genetically confirmed as Syngap1 Syndrome (Synaptic RasGTPase activating protein). This study aimed to show the importance of genetic testing and accurate diagnoses associated with syndromes for the planning and accomplishment of dental treatments. The new diagnosis allowed reorganization of the plan and was useful in decision-making for the clinical practice of dental treatment for patients diagnosed with Syngap1.

Indexing terms: Autism Spectrum Disorder. Dentistry. Genetics.

\section{RESUMO}

Apresentamos um paciente com diagnóstico clínico inicial de Transtorno do Espectro Autista nível 3 e geneticamente confirmado como Síndrome Syngap1 (proteína ativadora Synaptic RasGTPase). O objetivo deste estudo foi mostrar a importância de exames genéticos e diagnósticos precisos associados a síndromes na elaboração do planejamento e condução de tratamentos odontológicos. O novo diagnóstico possibilitou a reorganização do plano e pôde ser útil na tomada de decisão para prática clínica do tratamento odontológico de pacientes com diagnóstico de Syngap1.

Termos de indexação: Transtorno do Espectro Autista. Odontologia. Genética.

\section{INTRODUCTION}

The Autism Spectrum Disorder (ASD) is a disorder characterized by persistent impairment in reciprocal social communication, social interaction and repetitive patterns of behavior, interests or activities. These symptoms are present since early childhood and limit or impair the daily functioning. The stage at which the functional impairment

\section{$\boldsymbol{\nabla} \boldsymbol{\nabla} \boldsymbol{v}$}

1 Universidade Anhanguera de São Paulo. Faculdade de Odontologia. Av. Braz Leme, 3029, 020022-11, São Paulo, SP, Brasil. Correspondence to: AG ZINK. Email: <zinkpinho@yahoo.com.br>.

2 Faculdade de Odontologia da APCD. São Paulo, SP, Brasil.

$\boldsymbol{\nabla v} \boldsymbol{\nabla}$

How to cite this article

Zink AG, Pinho MD, Pinho MZ, Martins FB. Syngap1 syndrome and autistic spectrum disorder. RGO, Rev Gaúch Odontol. $2021 ; 69: e 20210041$. http://dx.doi.org/10.1590/1981-863720210004120190091 
is evident varies according to the individual's characteristics and his or her environment. These are developmental disorders with heterogeneous, multifactorial and complex genetic etiology with high heritability $[1,2]$.

SYNGAP1 syndrome is characterized as a neurodegenerative disorder with moderate to severe mental disability and is manifested in childhood. It is considered a syndrome because it encompasses several conditions. The first characteristic of this syndrome is the impairment in speech development and motor skills, such as sitting, standing and walking, besides comorbidities as ASD and epilepsy [3].

The strength of excitatory synapse is regulated in the central nervous system by controlling the number of a-Amino-3-hydroxy-5-methyl-4-isoxazolepropionic acid postsynaptic receptors (AMPARs) [4].

SYNGAP is a GTPase Ras/Rap (GAP) activating protein that is one of the main components of postsynaptic densities of the mammalian forebrain [5].

Neurodevelopmental disorders, such as nonsyndromic types of intellectual disability and Autism Spectrum Disorder (ASD), involve disturbances in the excitatory synaptic function. ASDs affect $1 \%$ of the general population and are characterized by deficits in social interactions, communication and manifestation of repetitive behaviors $[1,6]$.

A fundamental characteristic of the early stages of human brain development is based on sensory, cognitive and emotional experiences that determine the formation and refinement of neuronal circuits. Consequently, changes in these processes cause many psychiatric and neurodevelopmental disturbances [7]. Disorders related to neurodevelopment affect 3-4\% of the world population. The impact of these disorders presents a great challenge for clinicians, geneticists and neuroscientists. Mutations that cause neurodevelopmental disorders are commonly found in genes that encode proteins that regulate the synaptic function. The investigation of the underlying mechanisms using approaches of function gain or loss revealed changes in the structure, function and plasticity of the dendritic column, consequently modulating the formation of the neuronal circuit and thus increasing the possibility of neurodevelopmental disorders resulting from synaptopathies. One of these genes, SYNGAP1 has been shown to cause intellectual disability with comorbidity with Autism Spectrum Disorder and epilepsy [7].
In addition to cognitive impairment, the decrease in SYNGAP can affect the neurodevelopmental disorders that cause deficits in sensory processing. The biological mechanism of this decrease has been scarcely studied so far. According to Michaelson et al. [8], the decrease in SYNGAP in humans causes a sporadic neurodevelopmental disorder defined by cognitive impairment, autistic behaviors and epilepsy, and also leads to deficits in sensory processing related to touch. In vivo neurophysiological analyses in SYNGAP1 mouse models revealed that neurons in the upper lamina of the somatosensory cortex weakly encode information related to touch. This was caused by reduced synaptic connectivity and impaired intrinsic excitability in neurons in the somatosensory cortex of the upper lamina.

The variants of loss of function of SYNGAP1 are causally associated with intellectual disability, severe epilepsy, ASD and schizophrenia. Even though there are hundreds of genetic risk factors for neurodevelopmental disorders, this gene is unique due to the frequency and penetrance of variants of loss of function found in patients combined with the range of brain disorders associated with the pathogenicity of SYNGAP1 [9].

It is known that early therapeutic approaches provide considerable positive results, and in this context the study of genetics associated with ASD has great importance, since there are gaps to be filled [10].

Recent advances in the field of genetics, such as screening and investigation of the genome of individuals and relatives affected by ASD, promoted an explosion of information about the pathophysiology of these disorders. Even though ASD is apparently highly heritable, the transmission does not conform to Mendelian laws, thus it is unlikely that the condition is simply linked to the $X$ chromosome, dominant or recessive. Thus, the condition presumably involves several genes in different chromosomes interacting with moderate effect and composing the ASD [11].

This study aimed to show the importance of genetic tests and accurate diagnoses associated with syndromes in the planning and accomplishment of dental treatments for patients with autistic behavior.

\section{CASE REPORT}

Report of patient IJMCT, Caucasoid, aged 10 years, born in São Paulo, Brazil, showing autistic behavior, neurological disorganization, lack of verbalization, intellectual 
disability, sensory changes, epilepsy and some stereotypies. The patient attended the dental clinic for patients with special needs at APCD (São Paulo Dental Association) accompanied by the caretakers and diagnosed with Autism Spectrum Disorder (ASD). The ICD-10 F84 level 3 was described according to the DSMV1, requiring support for the accomplishment of all routine activities, including oral hygiene. The ASD levels are described in table 1, with a brief description of limitations that accompany each level.

During the evaluation, we observed behavioral changes, difficult socialization, lack of communication, little eye contact and lack of fine motor coordination. Conditioning sessions were proposed for outpatient dental treatment and preventive maintenance. Despite the difficulty for follow-up, the family was collaborative and performed daily oral hygiene maintenance due to the lack of motor coordination to perform the activity.

The initial approach was conducted following the Principles of the Son-Rise Program ${ }^{\circledR}$, which consists mainly of seeking eye contact, which is the most complex communication means for children with ASD. By eye contact, the person is able to communicate socially even without verbalization, thus the search for eye contact is important for the patient-professional relationship [12].

Two sessions were necessary to maintain good eye contact with the patient. During the sessions he became neurologically disorganized, bit his own hands several times and presented to be very uncomfortable with the session time.

After achievement of eye contact, the patient entered the clinic and the approach was performed on the floor close to the dental chair, which was the place where the patient spontaneously chose to stay for later move to the dental chair as the spontaneous acceptance and patient-professional interaction were improved.

Three sessions were required for the patient to spontaneously sit on the chair. Communication by figures was used to enhance the presentation of the proposed activity, initiating a new method of approach and communication with the person with ASD, proposed at the time and later published later [13]. The presentation of figures also caused disorganization of the patient and hand bite, although it is a viable option to approach people with ASD. During the sessions, no epileptic seizures or absences were observed.

The treatment was performed, including scaling, dental polishing and application of fluoride varnish. The patient was referred for prevention with semi-annual visits. The absence of verbalization impaired the initial patient-professional communication.

It was not necessary to use drug sedation, physical or mechanical restraint, even though he was a patient with ASD level 3. All actions were anticipated to reassure the patient, reduce the emotional instability and neurological disorganization. Besides the figures, we used music and social reinforcers. Participation of the family as supporters in all stages of care was essential in this initial approach period.

Half-yearly visits were maintained for prevention, a protocol suitable for any patient.

At the age of 15 years, 5 years after dental followup, he was referred to the Mendelics Genomic Analysis Laboratory by the medical doctor and a study of the exome

Table 1. TEA levels (DSMV-2014).

\begin{tabular}{|c|c|c|}
\hline Severity level & Social Communication & Restricted and repetitive behaviors \\
\hline Level 3 & $\begin{array}{l}\text { Serious deficits in verbal and non-verbal social communication skills; serious } \\
\text { damage to operation; great limitation in initiating social interactions; } \\
\text { minimal response to social openings that come from others. }\end{array}$ & $\begin{array}{l}\text { Behavioral inflexibility; } \\
\text { Extreme difficulty in dealing with change or other restricted } \\
\text { behaviors; } \\
\text { Great suffering / difficulty to change the focus. }\end{array}$ \\
\hline Level 2 & $\begin{array}{l}\text { Serious deficits in verbal and non-verbal social communication skills; } \\
\text { Apparent social damage even in the presence of support; } \\
\text { Limitation in initiating social interactions and reduced or abnormal response to } \\
\text { social openings that come from others. }\end{array}$ & $\begin{array}{l}\text { Behavioral inflexibility } \\
\text { Difficulty dealing with change or other restricted / repetitive } \\
\text { behaviors. } \\
\text { Suffering and / or difficulty changing focus or actions }\end{array}$ \\
\hline Level 1 & $\begin{array}{l}\text { In the absence of support, deficits in the media cause notable losses. } \\
\text { Difficulty in initiating social interactions and clear examples of atypical or } \\
\text { unsuccessful responses to the social openings of others. }\end{array}$ & $\begin{array}{l}\text { Behavioral inflexibility causes significant interference with } \\
\text { functioning in one or more contexts. } \\
\text { Difficulty in switching activities. } \\
\text { Problems for organization and planning. }\end{array}$ \\
\hline
\end{tabular}


was conducted with DNA extracted from peripheral blood, which resulted in the capture of approximately 200,000 exons from 20,500 genes using the Nextera Exome Capture system, followed by new-generation sequencing with Illumina HiSeq 2500.

Alignment and identification of variants were performed by bioinformatics protocols, using the GRCh37 version of human genome as reference.

The result found was SYNGAP1 (table 2), with clinical diagnosis of behavioral cognitive deficit (table 3).

SYNGAP1 was analyzed in full sequence for the entire coding region (by Sanger sequencing or NGS). When there is negative deletion/duplication of tests, MLPA qPCR must be performed. When negative, the update for exome sequencing can be considered for the detection of mutations in genes associated with phenotypes overlapping with mental disability and epilepsy.

The variant C.857 T> C was confirmed by sequencing by the Sanger method in the patient and was then investigated in his parents, being absent in both and presenting heterozygosity in the SYNGAP1 gene, promoting replacement of the leucine amino acid present in position 286 by proline (p.Leu286Pro) (table 4). Therefore, this variant occurred as a de novo mutation (i.e. not inherited from the parents), thus reinforcing its deleterious nature and also indicating negligible risk of recurrence. The position at which this replacement occurred is highly conserved in several biological species (PhyloP $>4$ ). Protein structure prediction softwares by computer analysis suggest that the variant is harmful.
According to a descriptive report issued by the laboratory where genetic sequencing was performed, the variant found in the patient's DNA was not previously reported in the medical literature, nor is present in nearly 61,000 Brazilian and foreign individuals with genetic sequencing performed up to that time [14].

Patients with Syngap1 present the following characteristics [14]:

- Epilepsy (in $84 \%$ of cases), half of which does not respond to epilepsy drugs;

- Autism Spectrum Disorder (in more than 50\% of cases);

- Delayed development;

- Intellectual disability;

- Hypotonia;

- Onset of walking around 2 years and 2 months (ranging from 14 to 30 months, up to 5 years);

- Damages in language development;

- One third of individuals are non-verbal until 5 years; those with verbalization make sentences of only one to five words;

- Dyspraxia (oral motor dysfunction);

- Flat foot;

- Eye abnormalities, including strabismus;

- Gastrointestinal problems, including constipation that requires drug management.

Table 2. GENE: SYNGAP1 (Synaptic Protein RAS-GTPase activator 1).

\begin{tabular}{lccc}
\hline Genomic Position & Variant/Consequence & Presence in & Classification \\
\hline Chr6:33.405.539 & c.857 T>C (p.Leu286Pro) ENST00000629380 & Heterozygosis (one copy) & Definitely pathogenic \\
\hline
\end{tabular}

Table 3. Diagnosis based on the exome result: Cognitive behavioral deficit.

\begin{tabular}{ll}
\hline Diagnosis & No OMIM $^{\circ}$ \\
\hline Cognitive behavioral deficit associated with the SYNGAP1 gene & 612621 \\
\hline
\end{tabular}

Table 4. SYNGAP1 Phenotype / Genotype.

\begin{tabular}{|c|c|c|c|c|c|c|}
\hline Location & Phenotype & Phenotype number MIM & Inheritance & Phenotype mapping key & Gene/Locus & Gene/Locus number MIM \\
\hline
\end{tabular}




\section{DISCUSSION}

Currently there is an increasing number of patients diagnosed with ASD, although in Brazil there are no official statistical data. This increase in newly diagnosed cases highlights the need of professionals prepared for specialized multidisciplinary care. Several options have been proposed to determine the diagnosis, such as genetic tests, laboratory examinations and clinical evaluation. Genetic mapping and accurate diagnosis can improve the prognosis in the process of development of patients, who can receive more customized therapies appropriate to their needs. In this case, the DNA variant C.857 T>C is presented in the differential diagnosis of ASD.

SYNGAP1 was first described in the literature in 2009 and there are still few reports of patients with this condition, and many still maintain a more severe diagnosis of ASD, classified as level 2 or 3 according to the DSM V classification [1,15] Genetic counseling is currently highly indicated in patients with conclusive diagnosis of ASD. In this case, the genetic diagnosis and the early approach facilitated the patient's adaptation and acceptance to dental treatment, and the recognition of limits for intellectual development. Patients with Syngap1 have intellectual disability associated with the condition, which differs from ASD in which not all individuals present intellectual disability. Some interventions in adaptive processes for conditioning must be performed in patients with intellectual disability.

SYNGAP1 is a negative regulator of Ras, Rap and AMPA traffic for the postsynaptic membrane, thus regulating not only the synaptic plasticity, but also the neuronal homeostasis. Recent studies about the neurophysiology of SYNGAP1, using SYNGAP1 mouse models, provided deeper insights on how signaling proteins and synaptic plasticity are regulated by SYNGAP1. This knowledge enhanced the understanding of the function of SYNGAP1 and suggests a potential target during the critical period of development, when the brain is more susceptible to therapeutic intervention [7] In this context, all early therapeutic intervention was extremely important for the patient, including the new ability to include preventive dental activities, even though he did not receive models adapted for intellectual disability and developmental delay. All structured material used to approach the patient was adapted for a person with Autism Spectrum Disorder.
In 3 of 94 patients with non-syndromic intellectual disability, Hamdan et al. [15] identified 3 different de novo heterozygous truncated mutations in the SYNGAP1 gene. All patients had delayed global development with delayed motor development, hypotonia, moderate to severe intellectual disability and severe language impairment, with a profile close to the patient described in this report. One patient had strabismus and two had epilepsy. There were no other dysmorphic features. The onset is in the first year of life and the clinical characteristics can be found in different combinations. Most patients have epilepsy (myoclonic, seizures also during sleep, absences or attacks, which can be sensitive to treatment with valproic acid). Other clinical aspects observed include hypotonia and unsteady gait. The sensitivity to treatment with valproic acid for patients diagnosed with SYNGAP1 and epilepsy rules out the indication of drug; patients with this diagnosis do not react to the use of valproic acid, minimizing improper indications when the initial clinical diagnosis is ASD and epilepsy. At the time of treatment, the patient was treated for epilepsy using valproic acid, which was removed after the genetic diagnosis.

A study by Santos et al. [11] found significant involvement of genes SHANK3, NLGN3, NLGN4, NRXN1, MDGA2, FHIT, HTR2A, SHANK2, GRIA3, ZNF778, PRKC, CDH15， DIAPH3， GCH1， GRM5， MARK1, SLC17A6, IMMP2L, BZRAP1, SYNGAP1, ANK3, MAP1A, GABRR2, LAMC3, LRRC7, LRRIQ3, CADPS1, NUFIP, SEMA3A, SNAP29, MBD2, GAD2, DGKH, PARD3, PIK3CG, RELN, NRCAM, LAMB1, WNT2, FOXP2, GRM8, UBE2H, A2BP1, ATP10A, CADPS2, CNTN4, CNTNAP2, DLGAP2, EGR2, EN2, GABRB3, MET, SLC4A10, DISC1, NPTX2, PCDH9, AUTS2 and RBFOX 1 in patients with ASD. Attention should be paid to genetic mapping and accurate diagnosis of patients for better customized follow-up, both therapeutic and using drugs.

The diagnosis considered "gold standard" for Autism Spectrum Disorders is performed by the molecular cytogenetic technique called "array comparative genomic hybridization" (aCGH), which is classified as the most efficient in the postnatal diagnosis of probands.11 However, many doctors still rely only on clinical observation with the support of a multidisciplinary team and application of questionnaires for clinical diagnosis, ruling out the possibility of genetic investigation [16].

Genetic counseling is fundamental for parents before planned pregnancies [3], especially in cases of relatives with some genetic condition. 
Since there is still no cure and no possibility of gene therapy for people diagnosed with the rare SYNGAP1 syndrome, multiprofessional treatment is possible by a team including a neurologist, orthopedist, dentist, therapists, psychologists and other health professionals, and clinical measures should be adopted to reduce the suffering of the patient and relatives. Discovering the genetic factor of a person with clinical diagnosis of Autism Spectrum Disorder specifically helps to stratify this population and to form scientific study groups, improving the knowledge on these rare conditions and providing knowledge to healthcare professionals.

The dental follow-up of the patient IJMCT, aged 16 years, is still maintained in an outpatient clinic with approach and management techniques for patients with intellectual disability, muscle hypotonia and epilepsy. Communication figures were removed, which are often used for patients with autism spectrum disorder. We observed that the excess of figures was always accompanied by neurological disorganization with hand bites. The counting of time to allow the predictability of actions was maintained, as well as eye contact. Verbal communication had better result than communication by figures specific for ASD in the follow-up of this patient.

\section{CONCLUSION}

The diagnosis of Syngap 1 syndrome in the patient with autistic behavior enhanced the treatment planning and accomplishment, respecting the limitations and learning potential of the patient, avoiding the unnecessary use of specific techniques used for conditioning and treatment of patients with autism spectrum disorder.

\section{Collaborators}

AG ZINK, lead author, researcher in the field of autism, patient care, conditioning, text construction and responsible by the terms of consent. MD PINHO, clinical patient care, conditioning, author of the photographs, anamnesis, survey of reports. MZ PINHO, literature review, formatting. FB MARTINS, advisor in the construction of the text and assembly of the article.

\section{REFERENCES}

1. American Psychiatric Association. DSM-V: manual diagnóstico e estatístico de transtornos mentais. Porto Alegre: Artmed; 2014.

2. Gomes PT, Lima LH, Bueno MK, Araújo LA, Souza NM. Autism in Brazil: a systematic review of family challenges and coping strategies. J Pediatr. 2015;91(1):111-21. http://dx.doi. org/10.1016/j.jped.2014.08.009

3. Asadi S, Amjadi H, Valizadeh G, Hosseinpour R, Jamali M. SYNGAP1- Related Intellectual Disability Syndrome. Arch Neurol \& Neurosci. 2018;1(4):1-5. http://dx.doi.org/10.33552/ ANN.2018.01.000519

4. Chih-Chieh W, Richard GH, Benjamin JH. SynGAP regulates protein synthesis and homeostatic synaptic plasticity in developing cortical networks. PLoS One. 2013;8(12):e83941. http://dx.doi.org/10.1371/journal.pone.0083941

5. Walkup WG, Mastro TL, Schenker LT, Vielmetter J, Hu R, lancu $A$, et al. A model for regulation by SynGAP- a1 of binding of synaptic proteins to PDZ-domain 'Slots' in the postsynaptic density. Elife. 2016;13(5):e16813. http://dx.doi.org/.7554/ eLife. 16813

6. Kogan MD, Blumberg SJ, Schieve LA, Boyle CA, Perrin JM, Ghandour RM, et al. Prevalence of parent- reported diagnosis of autism spectrum disorder among children in the US, 2007. Pediatrics. 2009;124(5):1395-403. http://dx.doi.org/10.1093/ nar/gkr1145

7. Jeyabalan N, Clement JP. SYNGAP1: Mind the Gap. Front Cell Neurosci. 2016;10:32. http://dx.doi.org/10.3389/fncel.2016.00032

8. Michaelson SD, Ozkan ED, Aceti M, Maity S, Llamosas N, Weldon M, et al. SYNGAP1 Heterozygosity Disrupts Sensory Processing by Reducing Touch- Related Activity within Somatosensory Cortex Circuits. Nat Neurosci. 2018;21(12):1-13. http://dx.doi.org/10.1038/s41593-018-0268-0

9. Kilinc M, Creson T, Rojas C, Aceti M, Ellegood J, Vaissiere $T$, et al. Species-conserved syngap1 phenotypes associated with neurodevelopmental disorders. Mol Cell Neurosci. 2018;91:140-150. http://dx.doi.org/10.1016/j.mcn.2018.03.008

10. Ribeiro CM. Estudo de genes candidatos aos transtornos do espectro autista [tese]. Universidade São Paulo. São Paulo; 2013.

11. Santos CA, Melo HCS. A genética associada aos transtornos do espectro autista. Minas Gerais: Conexão; 2018.

12. Tolezani M. Son-Rise uma abordagem inovadora. Rev Autismo Info. 2010;1(0): 8-10.

13. Zink AG, Diniz MB, Rodrigues Dos Santos MT, Guaré RO. Use of a picture exchange communication system for preventive procedures in individuals with autism spectrum disorder: pilot study. Spec Care Dentist. 2016;36(5):254-9. http://dx.doi. org/10.1111/scd.12183

14. Berryer $\mathrm{MH}$. Mutations in SYNGAP1 cause intellectual disability, autism, and a specific form of epilepsy by inducing haploinsufficiency. Hum Mutat. 2013;34(2):385-94.

15. Hamdan FF, Gauthier J, Spiegelman D, Noreau A, Yang Y, et al. Mutations in SYNGAP1 in autosomal nonsyndromic mental retardation. N Engl J Med. 2009;360:599-605. http:// dx.doi.org/10.1056/NEJMoa0805392

16. Menezes SA, Zink AG. Abordagem lúdica do paciente com transtorno do espectro autista para o tratamento odontológico. Odontol Clín-cient. 2015;14:669-673.

Received on: 3/6/2019

Final version resubmitted on: 5/4/2020 Approved on: 2/6/2020 